\title{
A 'crise de paradigmas' nas Ciências Sociais, uma questão relativa à teoria da história?
}

\author{
Diogo da Silva Roiz
}

RÜSEN, Jörn. Razão histórica. Teoria da história: os fundamentos da ciência histórica. Tradução de Estêvão de Rezende Martins. Brasília: Ed. UNB,2001, 194p.

Quando Hayden White publicou, em 1966, o ensaio O fardo da história (depois agrupado em seu livro de ensaios: Trópicos do discurso, de 1978), o questionamento sobre um nível médio epistemologicamente neutro dos historiadores estarem entre a arte e a ciência no plano de sua prática e de sua escrita ainda não era tão contundente, como viria a se tornar após "maio de 1968" e das críticas de Michael Foucault em seu livro Arqueologia do saber, de 1969 , e, mais ainda, depois da queda do "Muro de Berlim" em 1989 e do fim da URSS no início da década de 1990, que vieram a estilhaçar os projetos políticos marxistas, embora sua herança teórica ainda hoje seja bastante profícua. Todavia, já naquela época, e nos anos de 1970 quando publicaria o livro Meta-história, Hayden White indicava que a História era um tipo específico de discurso, um artefato verbal em prosa sobre o passado, e nele náo haveria nenhum controle experimental por parte dos historiadores (e filósofos da história). A História seria uma representação do passado, assim como as fontes utilizadas pelo historiador já o seriam. E por isso ela não seria uma ciência, estando mais próxima da arte, uma vez que seu discurso não era realista e o que os historiadores faziam era uma construção de versóes que se diversificavam de acordo com as circunstâncias da época. $\mathrm{Ou}$ ainda, de acordo com os lugares sociais de onde estivessem falando, 
dos problemas que levantavam e os instigavam em suas pesquisas. Para ele a 'história vivida' não traria um sentido, ou mesmo uma lógica interna no seu desenrolar, ou mesmo uma racionalidade, que seriam reconstruídas pelo historiador. Os historiadores, ao escreverem sobre as sociedades passadas, é que produziriam um efeito explicativo, e os acontecimentos seriam convertidos dentro de um sentido, apenas retrospectivamente elaborado, e de acordo com as 'urdiduras' de enredo usadas pelo historiador. Para Hayden White, a 'realidade concreta' náo estaria nos eventos agrupados e inquiridos pelo historiador, mas seria uma construção da linguagem, e assim a narrativa histórica não seria tão simplesmente uma apreensáo de dados exteriores, mas sim a construçáo de 'visóes de mundo do historiador. A historiografia, nesse sentido, seria uma reconstrução de enredos já conhecidos, por meio de uma linguagem figurativa, e não meramente técnica, ou mesmo racional e científica. Portanto, os questionamentos de Hayden White ao ofício dos historiadores, entre as décadas de 1960 e 70, impunham uma reelaboraçáo, ou pelo menos, um questionamento e uma revisão das 'teorias da história', e que se tornou mais latente nas últimas décadas, por motivos acima expostos.

Acreditando-se, desse modo. que uma Teoria da história deve necessariamente possuir (pelo menos) uma Filosofia da história, isto é, uma interpretaçáo do processo histórico segundo um fim previamente estabelecido, ainda que em um tempo não programado, com vistas a se inquirir o sentido e as leis que diagnosticariam e proporcionariam o movimento de transformaçōes e permanências entre as sociedades passadas e as sociedades presentes; um Estilo, quer dizer, uma forma específica dos historiadores se expressarem aos pares e ao público, num nível de articulação possível entre o lugar social de onde falam, com sua prática de pesquisa e a sua escrita; e um Método, ou mais precisamente, procedimentos de pesquisa que lhe permitam inquirir e interpretar as sociedades passadas. Nesse sentido, pelo menos duas perguntas seriam fundamentais: qual a utilidade da teoria da história para os historiadores? Qual a importância das teorias e como os historiadores as incorporariam em sua escrita?

A importância desses questionamentos se encontra na observaçấo de que existe um consenso relativo entre 
vários autores (dentre os quais, Michel Vovelle, Pierre Villar, E.P Thompson, Perry Anderson, Eric Hobsbawm) de que as questóes teóricas seriam pouco discutidas e enfrentadas pelo historiador, e às vezes demasiadamente discutidas por filósofos e cientistas sociais (como Condorcet, Voltaire, Hegel, Marx, Durkheim, Weber, e mais recentemente, L. Althusser, M. Foucault, P. Bourdieu, C. Castoriadis), ocasionando, desse modo, mais uma apropriação de modelos teóricos dos filósofos e cientistas sociais pelos historiadores, do que a produçáo de teorias por parte dos historiadores. E, além disso, após o movimento estudantil de 'maio de 1968' (na França e em outros países), supóe-se que teria aumentado o descrédito e a não viabilidade dos principais modelos teóricos herdados do século XIX, tais como: o(s) Iluminismo(s), o(s) Positivismo (s) e o(s) Marxismo(s), e isso resultaria em um distanciamento ainda maior por parte dos historiadores das questóes teóricas e metodológicas de seu ofício profissional. Isso, em parte, porque aqueles modelos teóricos consagrados e herdados dos séculos XVIII e XIX, e que almejaram atingir por meio de suas "Filosofias da história" a realização de seus projetos políticos, revelaram-se, no século XX, sem a mesma força explicativa e sem a mesma capacidade de realização 'na prática'. Fundamentalmente, porque o projeto de uma sociedade globalizada e harmonizada pelas luzes do saber, no Iluminismo, de uma sociedade humanizada pelo saber científico, no Positivismo, e de uma sociedade justa e sem divisóes de classes, no Marxismo, demonstraram-se ineficientes quanto ao próprio movimento histórico que veio a tornar irrealizáveis, na prática, cada um daqueles projetos específicos. Por outro lado, supóe-se também que os desdobramentos do movimento dos Annales na França após a década de 1960, segundo muitos autores (dentre os quais se encontra François Dosse), teriam sofrido uma mudança significativa com relação aos projetos anteriores das duas primeiras geraçóes, ao desconsiderarem o conceito de progresso e de racionalidade, e ao rejeitarem a questão do sentido na História, e se aproximarem muito do irracionalismo’ pós-estruturalista e da interpretação 'circular' da história produzida na Antigüidade Clássica.

Nesse momento de 'crises' do discurso histórico e das teorias da história, o livro de Jörn Rüsen Razão histórica, originalmente publicado em 1983 na Alemanha, e somente 
traduzido no Brasil em 2001, com o acréscimo de um quarto capítulo, escrito em 1998, sobre a questão da narrativa e do sentido na história (onde discute principalmente com Paul Veyne e Hayden White), quis ao mesmo tempo responder às críticas de autores como Hayden White, Paul Veyne e Michel Foucault às teorias da história e ao discurso do historiador, e operar uma reconstrução das teorias da história, com vistas a delimitar suas características e o seu papel no ofício dos historiadores, quando recortam seus objetos de pesquisa, definem suas fontes e suas abordagens, assimilam um estilo à sua escrita da história e buscam inquirir e interpretar as sociedades passadas. Assim os questionamentos: como definir a questão do sentido na história? Como definir um estatuto de cientificidade e de racionalidade no discurso histórico? Como pensar a questấo do progresso no processo histórico? Foram os problemas levantados por esse historiador e com os quais intentou abordar possíveis respostas na sua obra.

O livro foi dividido, na edição brasileira, em quatro capítulos, cada um dos quais visando enfrentar um duplo dilema: o das críticas internas e externas à História; e da fun- ção das teorias na escrita da história. Procurou assim rastrear, de início, as características e a função de uma teoria da história. Para ele, a "teoria não é mais que uma elaboração superficial dessa constante reflexão do sujeito cognoscente sobre si mesmo(...) essa reflexão se efetiva, em correlação com o objeto primário do pensamento: a 'história' (...) [nesse sentido a] teoria da história arti-cula-se com a auto-reflexão do pensamento histórico, que se processa no trabalho quotidiano da pesquisa histórica” (2001: 25-6). Nesse sentido, buscou demonstrar "que o olhar dos historiadores passa dos objetos de seu conhecimento científico a seus princípios, como eles surgem e para que são tematizados" e assim o que a teoria "analisa, como fundamento da ciência da história, náo pode ser tratado independentemente das razóes e das finalidades dessa atividade" (2001: 26). Portanto, a teoria da história "tem de apreender (...) os fatores determinantes do conhecimento histórico que delimitam o campo inteiro da pesquisa histórica e da historiografia, identificá-los um a um e demonstrar sua interdependência sistemática. E como a pesquisa e a historiografia nada têm de estático, cabe a teoria mostrar como esse 
sistema é um processo dinâmico" (2001: 29). Para tanto, o autor indica que o historiador articula essas reflexóes dentro do que definiu como 'matriz disciplinar', onde estariam agrupados cinco elementos: idéias, métodos, formas, funçôes e interesses. Segundo ele, "uma 'matriz disciplinar' é uma explicação teórica do tipo de racionalidade da constituição histórica de sentido" (2001: 161). Portanto, a história, segundo ele, seria científica porque "ciência é método" (2001: 98).

Em sua argumentação se pauta na historiografia alemã e em autores como J. Burckhardt, J. Droysen, J. Habermas, R. Koselleck, E. Carr e A. Schaff, em função de acreditar que existe uma racionalidade, um sentido, um progresso, que delimitam as características do processo histórico, quando os historiadores buscam analisar os homens e as sociedades no tempo, e nesse sentido, talvez se agrupe ao que é hoje denominado 'neo-positivismo'. Assim, critica a análise 'irracionalista' sobre a história levantada por Michel Foucault, as restriçóes apontadas por Paul Veyne quanto ao nível de sentido da escrita e da possibilidade de interpretação do passado, e ao questionamento de Hayden White sobre o nível de verdade e de cientificidade na escrita da história, enquadrando-a em um tipo de arte. Mais do que Marc Bloch e Fernand Braudel que acreditaram que a História não era propriamente uma ciência, mas "uma pesquisa cientificamente conduzida", o autor leva ao extremo a afirmação, procurando demonstrar os níveis de cientificidade da pesquisa histórica e querer constatar que a História também é uma ciência, ainda que peculiar. Para ele "a cientificidade da ciência da história deve ser estabelecida e descrita justamente no que tem de peculiar, que produz o constructo significativo chamado história (...) História como ciência é a forma peculiar de garantir a validade que as histórias, em geral, pretendem ter. Histórias narradas com especificidade científica são histórias cuja validade está garantida mediante uma fundamentação particularmente bem feita" (RÜSEN, Jörn. 2001: 96-7). Pois, "narrar é uma prática cultural de interpretação do tempo, antropologicamente universal" (2001: 149).

Nesse sentido, diferentemente de Hayden White que almejou, entre as décadas de 1960 e 70 (e mesmo em pesquisas mais recentes), demonstrar que a História é um artefato discursivo em prosa, sen- 
do um tipo específico de literatura, Jörn Rüsen objetivou, nas décadas de 1980 e 1990, estabelecer que a História, quando cientificamente conduzida por meio de procedimentos empíricos e teóricos adequados, torna-se um tipo específico de ciência. E a teoria da história, nesse sentido, teria uma função primordial, pois, "no estudo de história, a teoria desempenha um papel importante na profissionalização didática dos historiadores. Esse papel consist[iria] em transmitir aos historiadores em formação uma concepção sólida da especificidade profissional de sua ciência" (2001:38).

Portanto, a instigante leitura proporcionada pelo livro Razáo histórica, de Jörn Rüsen, revela antes uma 'crise' da História e das Ciências Sociais, um período de definição do que seja a ciência e a arte, no âmbito específico daquelas áreas do saber; ainda que o autor se paute por defender a cientificidade da história, e, portanto, escolha um dos extremos. 